\title{
Correction: Clinical anthropometrics and body composition from 3D whole-body surface scans
}

\author{
B. K. Ng • B. J. Hinton - B. Fan · A. M. Kanaya - J. A. Shepherd
}

Published online: 25 November 2020

(c) The Author(s), under exclusive licence to Springer Nature Limited 2020

Correction to: European Journal of Clinical Nutrition https://doi.org/10.1038/ejcn.2016.109

The original version of this Article omitted the following text from the Table 3 legend:
Body volumes are in units of cubic feet as reported directly by the device manufacturer, where 1 cubic foot $=$ 28.32 L.

The authors apologise for any inconvenience caused by this missing text. 